\title{
ESTIMATE THE EFFECT OF THE DIFFERENCES OF BROILER DIETS ON PERFORMANCE AND BLOOD BIOCHEMICAL PARAMETERS
}

(With 11 Tables)

\author{
By \\ I.A. OTHMAN and A.J. CHEKH SULIMAN \\ (Received at 12/3/2011)
}

تقييم أثر اختلاف الخلطات العلقية المقدمة لاجاج اللحم على الكفاعة الإنتاجية

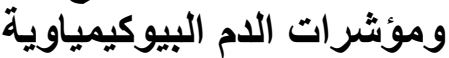

إياد عثمان ، عبد الجبار الشبخ سلبيان

أجريت تجربة حقلية لدر اسة اثر مستويين غذائيين مختلفين على المكونات الدموية

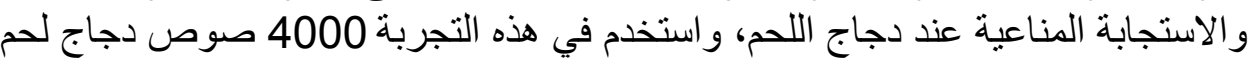

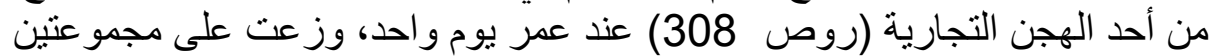

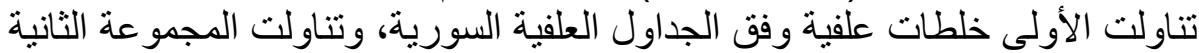

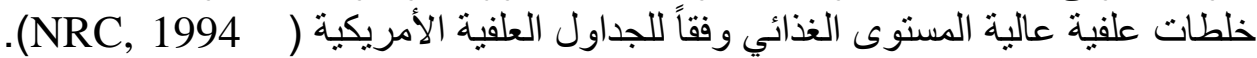
استمرت التجربة خمس أسابيع، ووزنت الطيوت الطيور الحية وتم حساب كمية العلف المستهلكة

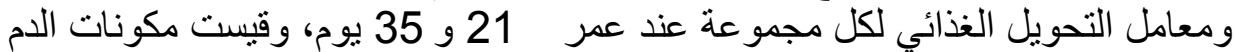

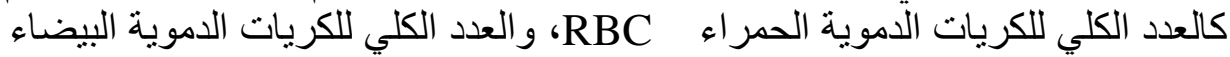

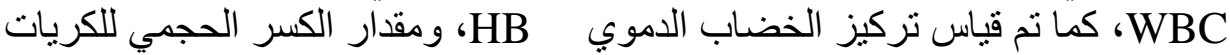

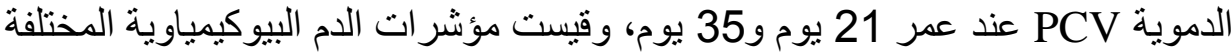

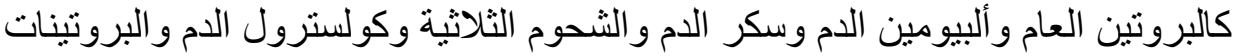
الشحمية العالية الكثافة و المنخفضة الكينة الكثافة

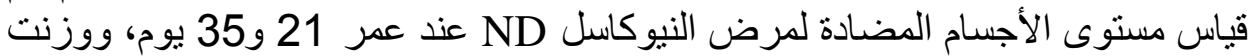
الأعضاء المناعية كالطحال و غدة فابريشيوس وكذللك الكبد في نهاية التجربة. أظهرت التهرت

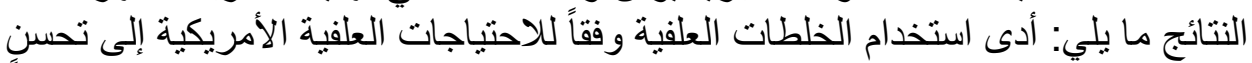

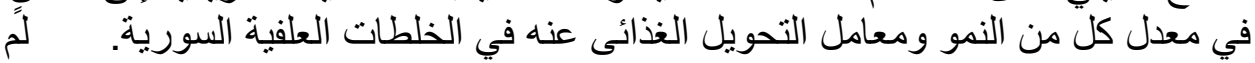

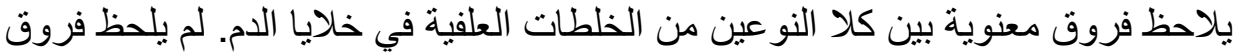

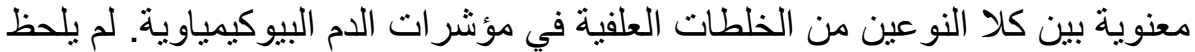

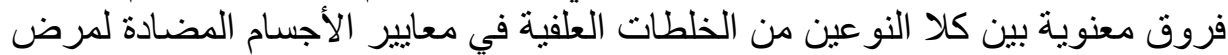

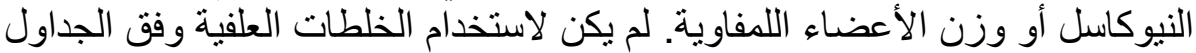

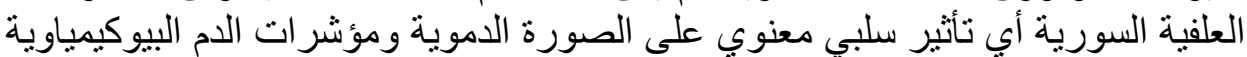
و الاستجابة المناعية الخلطية.

\section{SUMMARY}


A trial was carried out to study the effect of using two different nutrients density broilers diets. Four thousand one day-old chicks of commercial meat line (ROSS308) were used in the trial. The birds were distributed into two groups of 2000 birds each, the first group fed with diets according to Syrian feed tables and the second one fed with diets according to NRC, (1994). The experiment lasted for 5 weeks. RBC count, WBC count, hemoglobin concentration, packed cell volume at 21 and 35 days was estimated. Serum biochemical parameters at 21 and 35 days, weight immune organs were also investigated and immune response against ND vaccinations at 21, 35 and days was carried out. Results showed as follows: Using diets according to NRC, (1994) achieved the better growth speed and FCR than diets according to Syrian feed tables. There are no significant differences in RBC count, WBC count, hemoglobin concentration, packed cell volume at 21 and 35 days of age. There are no significant differences in serum biochemical parameters at 21and 35 days of age. There are no significant differences in weight of immune organs and immune response against ND vaccinations at 21, 35 days of age. There were no negative effects of using diets according to Syrian feed tables on blood profile, serum biochemical parameters and humoral immune responses.

Key words:

\section{INTRODUCTION \\ مقدم-ة}

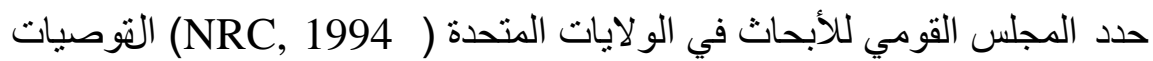

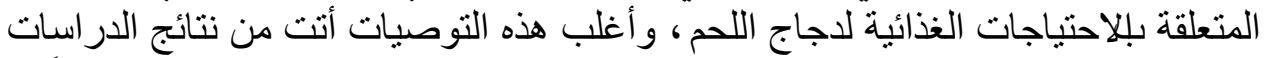

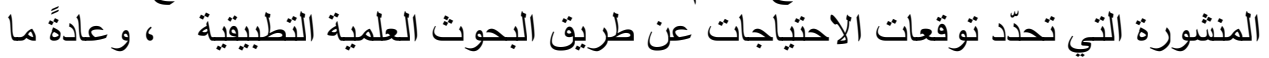

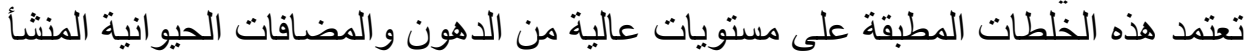
لتحقيق القيم الغذائية التي نصح بهن التهات (NRC, 1994).

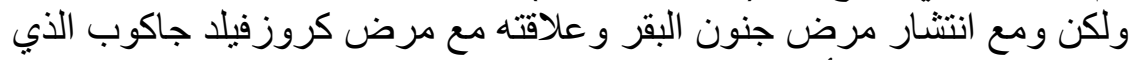

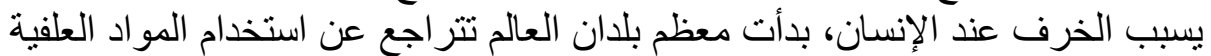

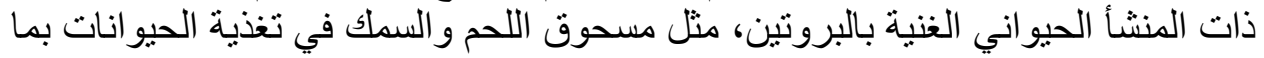

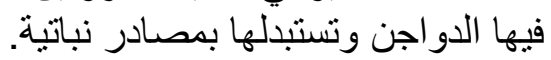




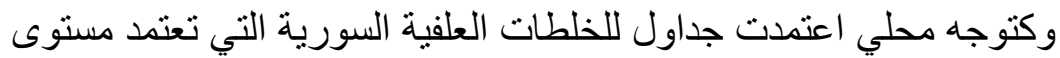
غذائي منخفض (الجداول العلفية السورية - 1987)، و وعمل عدد من اعن الباحثين في سورية

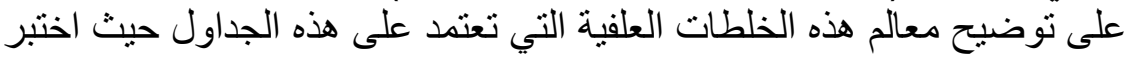

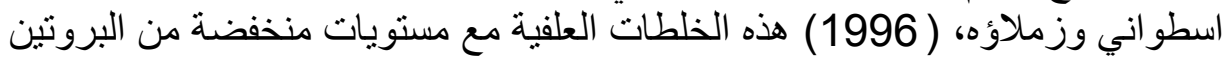

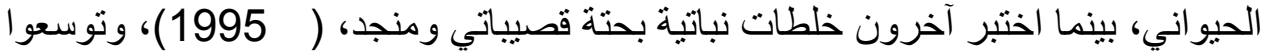

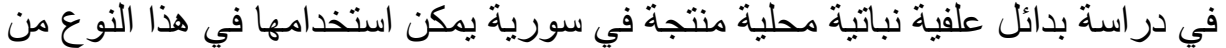

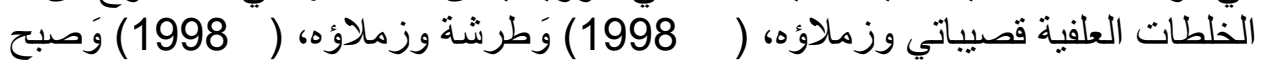
وزملاؤه، (1998). وقد أشارت عدة دراسات إلى أن احتباجات دجاج اللحم للأحماض الآمينية الأكثر

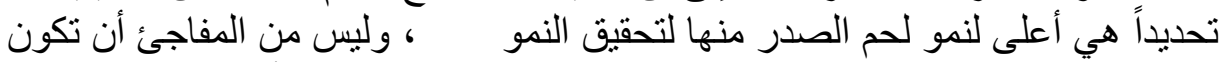

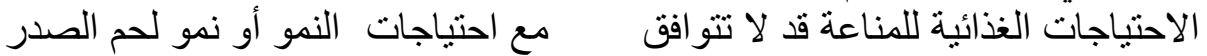

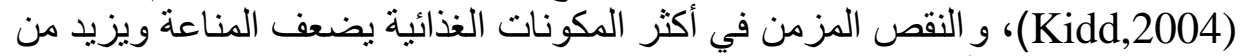

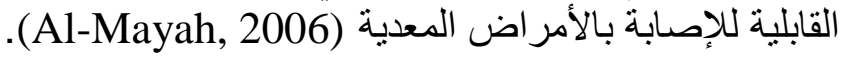

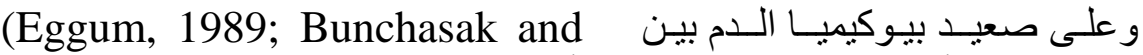
أن بروتين المصل الكلي يتأثر بشكل سريع مباشرة مع كمية ونوعية Slipasorn, 2005)

اما بالنسبة للإستجابة المناعية فقد قاد ذلك إلى إجر اء العديد من الأبحاث لتقييم

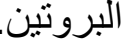

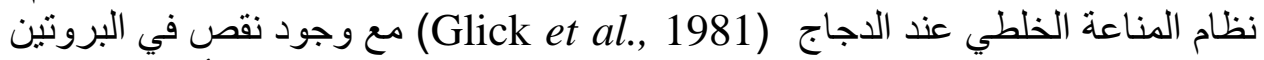

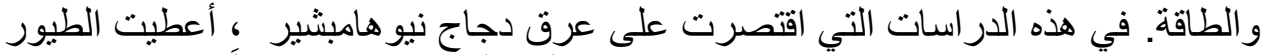

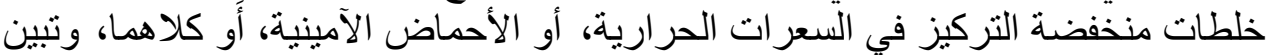

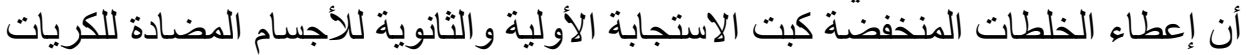

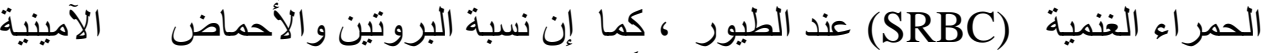

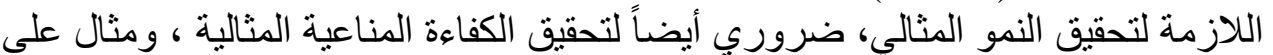

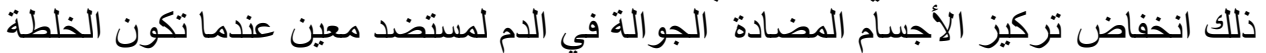

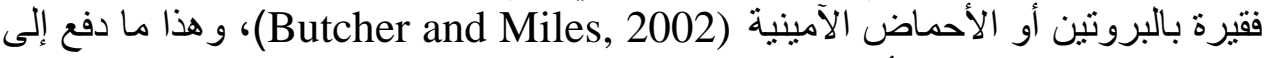
إجر اء هذه الدراسة لسبر تأثير اختلاف المستوى الغذائي ما بين الخلطات العلفية الإنية المعتمدة

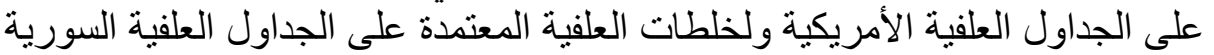

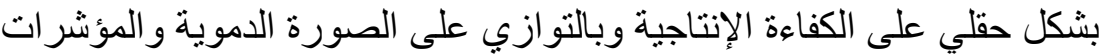

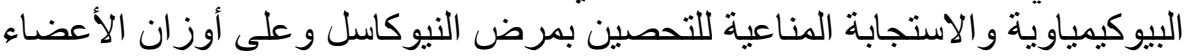

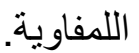

\section{MATERIALS and METHODS مواد وطرائق البحث}

\section{1 - 2 - تجربة الأداء الإنتاجي:}

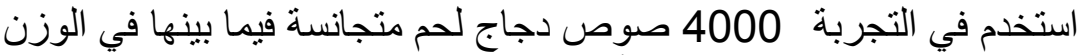
ودون التمييز بين الذكور والإناث ، ومن أحد الهجن التجارية بمتوسط وزن ( 400.15)غاغ فئان. 
تمت رعاية الطيور في حظيرة تجارية في بلدة قمحانة حماة و التي تعتمد النظام المفتوح،

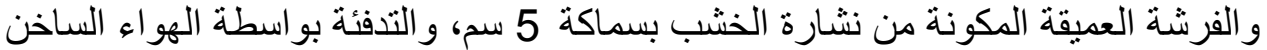
للتحكم بدرجة الحر ارة داخل الحظبرة، والتهوية سلبية التية عن طريق 4 ساحبات الهواء.

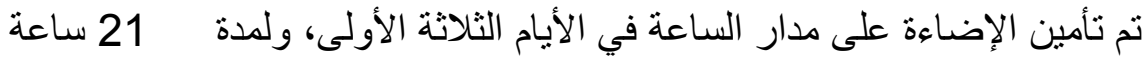

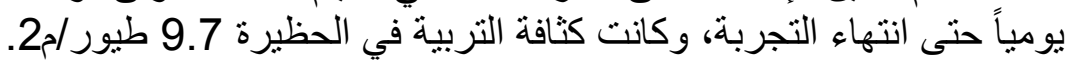

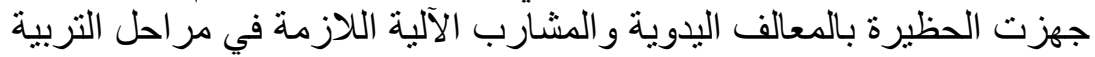

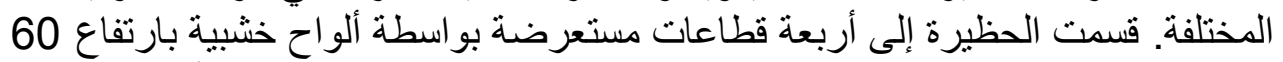

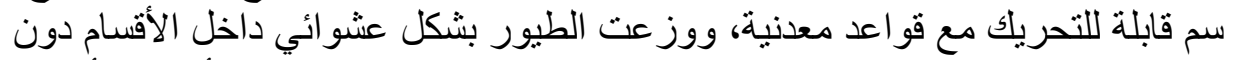

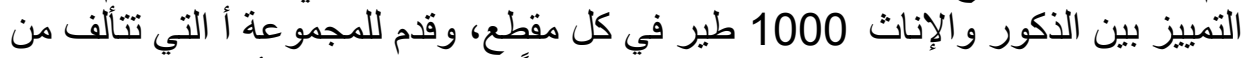

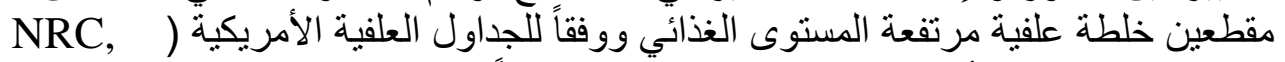

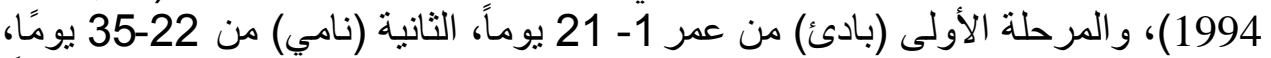

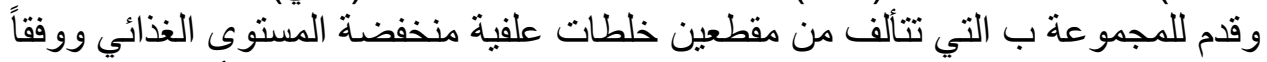

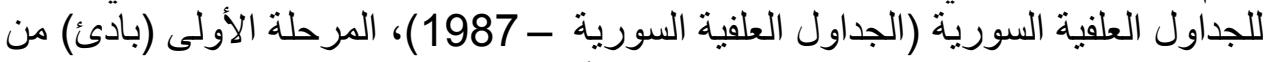

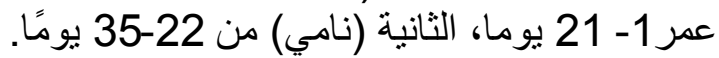

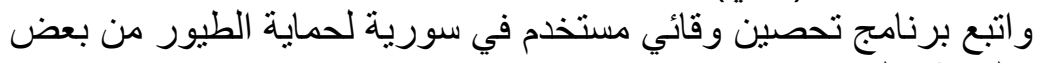
الأمر اض الهامة و المنتشرة اللقاح المقدم

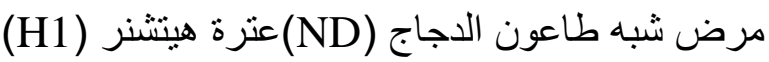

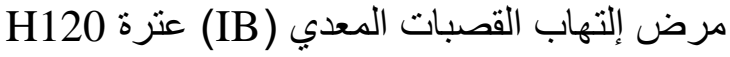
6 مقن تحت جلد الرقبة لقاح معطل لمرض شبه طاعون الدجاج الدجاج (ND) 15 قطرة في العين 23 قطرة في العين مرض شبه طاعون الدجاج (ND) عترة كلون./ داعم/

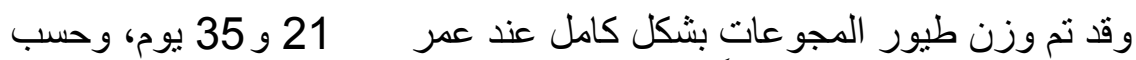
العلف المستهلك لكل مجمو عة أسبو عياً، وحسب بالتالي معامل تحويل كايل العلف بهذين اليوم طريقة إعطاء اللقاح 6 2 - تركين.

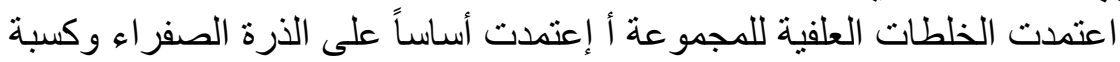

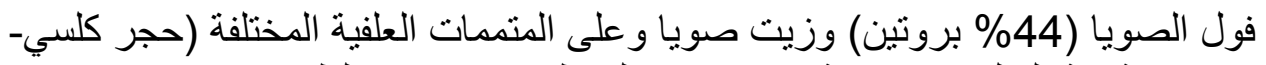

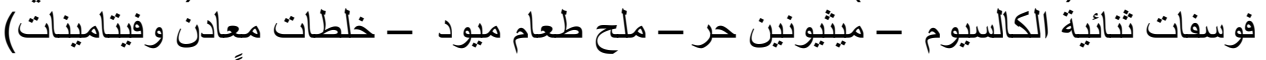
بحيث تفي الخلطات العلفية المركبة بالاحتياجات الغذائية لاجاج اللحم وفقاً لجداول (NRC, 1994)

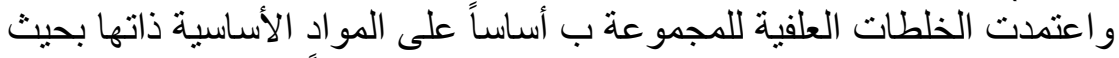

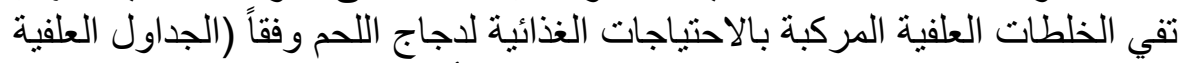

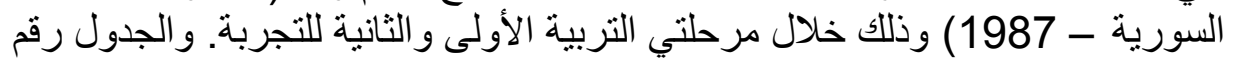


(1) يبين تركيب الخلطات العلفية، والجدول رقم ( 2) يبين تحليل الخلطات العلفية المستخدمة في التجربة. و هذاً وقد تساوت الخلطة فئات العلفية المقدمة في نسبة الطاقة إلى البروتين الخام

$$
3 \text { - تقدير الصورة الكوة وفي نفس المرحلة: }
$$

تم اختيار عينة عشو ائية مؤلفة تضم عشرة الفرة طيور من كل مقطع بو اقع عشرين

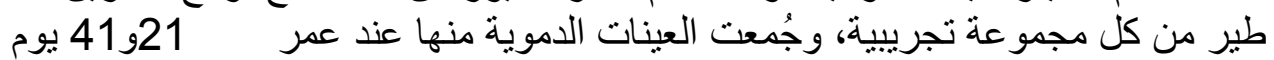
بواسطة محقن (قياس 3مل) أضيف إليه

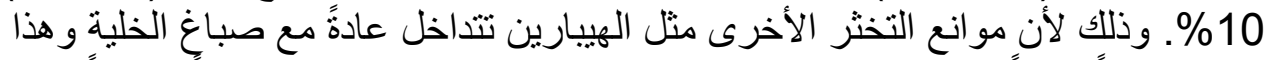

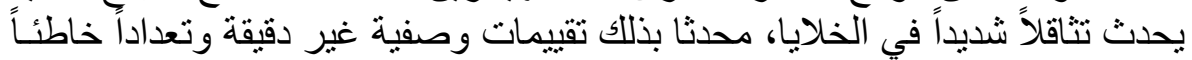

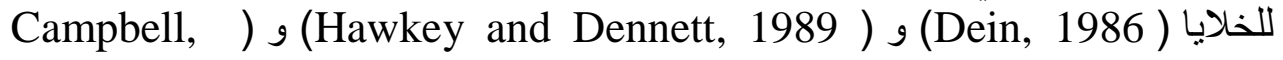

تم تحريك المحقن بعد أخذ عينة الدم بشكل جيد من أجل مزج العينة الدموية جيداً (1988

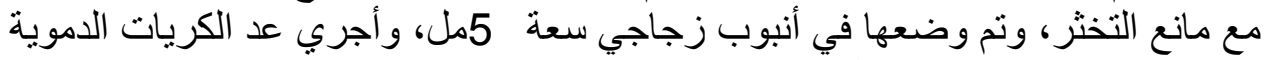
الحمر اء و البيضاء الكلي بشكل مبانشر ، وتم قياس الـ الـ 4 - قياس المؤشرات الآدموية:

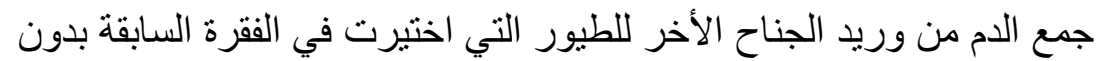

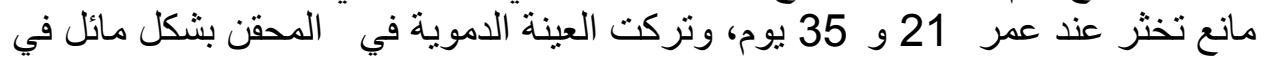

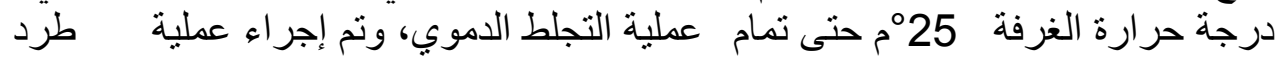
مركزي لمدة 30 ثانية في المثفلة على السرعة

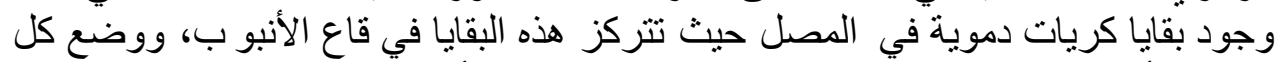

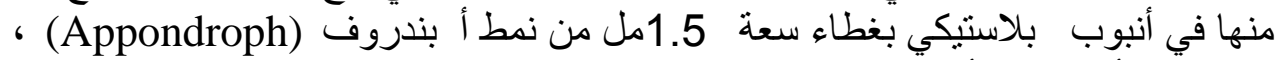

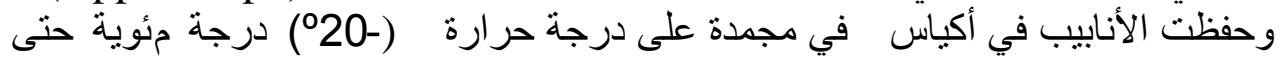

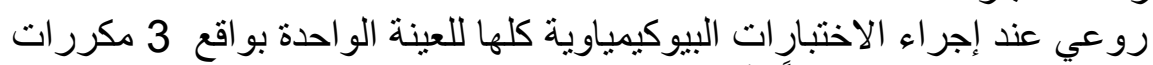
مو عد إجر اء الاختبار.

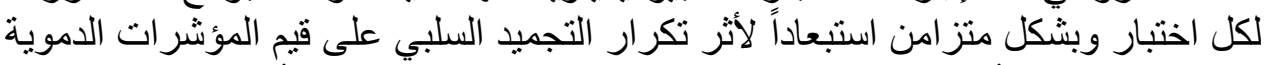

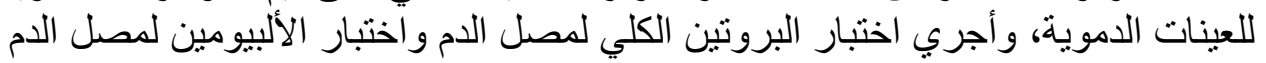

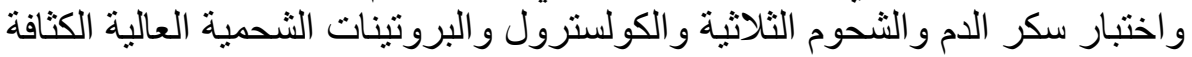

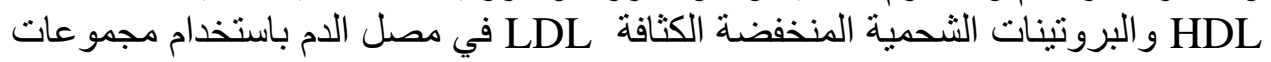

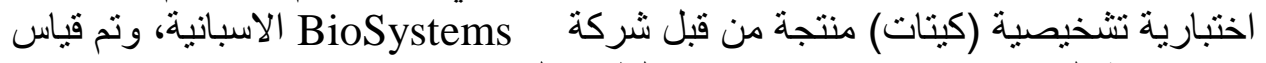

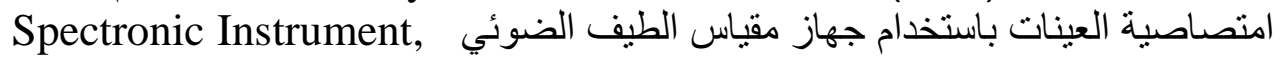
.Model.2001/4 5 - قياس مستوى الأجسام المضادة لمرض النيوكاسل:

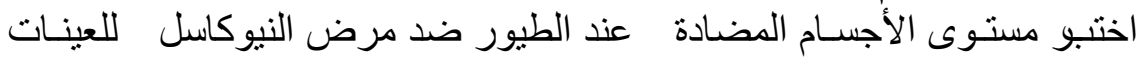

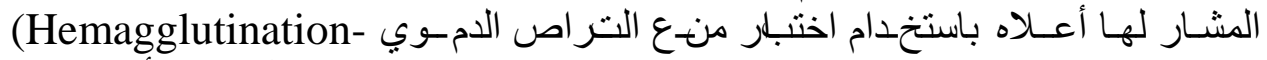

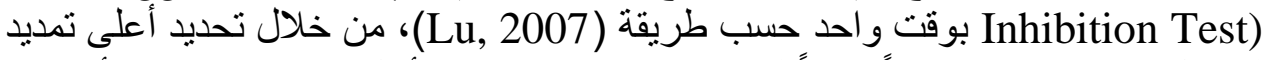
للمصل (معيار) يسبب منعاً كاملاً لتر اص كريات الدم، ومن أجل در اسة التمديدات أجريت 


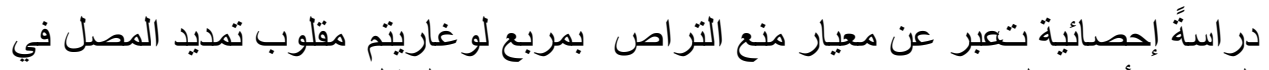

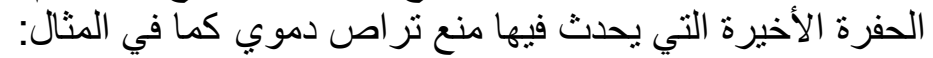

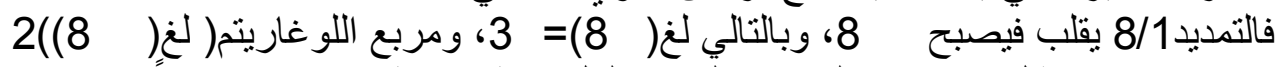
9=2(3)= 6 - وزن الأبيحة والأعضاء:

اختير20 طير من كل مجموعة بشكل عشو الأي و عند عمر 35 يوم لتحديد وزن

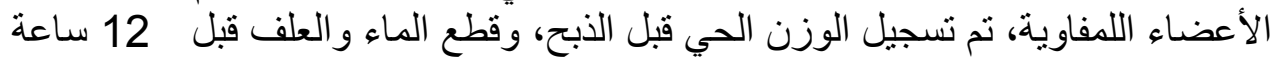

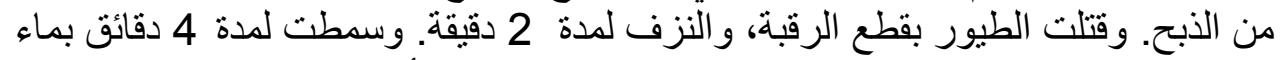

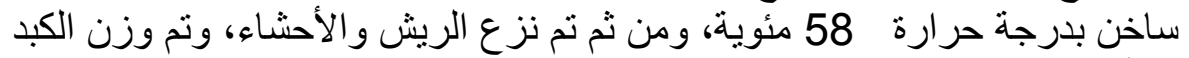

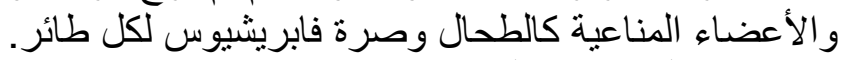
7 - الاراسة الإحصائية:

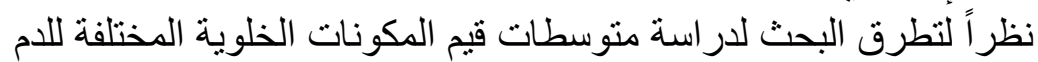

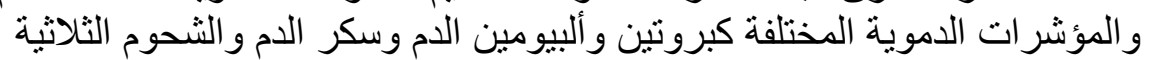

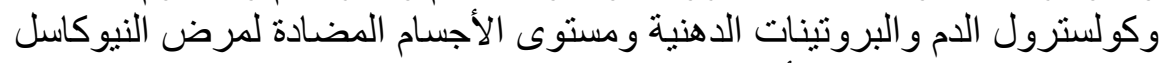

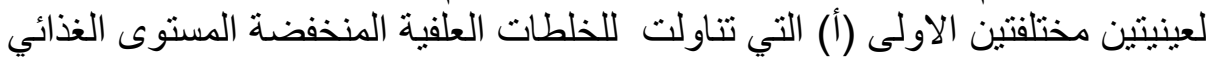

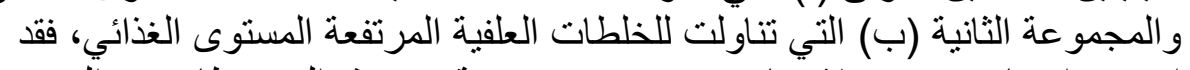

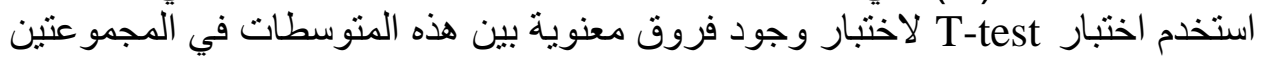

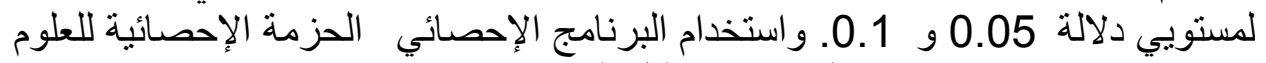
الاجتماعية (SPSS, 2008) لمقارنة وتحليل النتائج الإحصائية.

\section{RESULTS}

النتائــج

\section{DISCUSSION}

\section{المناقثـة}

يبين الجدول رقم 3 منوسط أوزان الطيور عند عمر 21 يوم و 35 يوم ويلاحظ

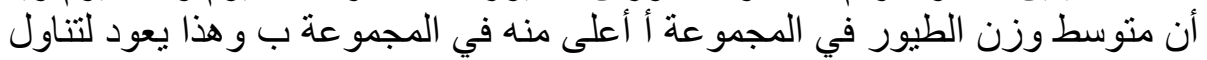

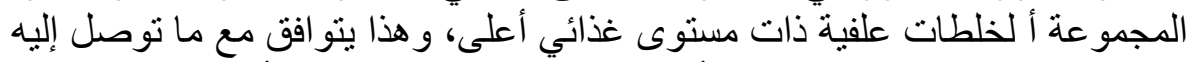

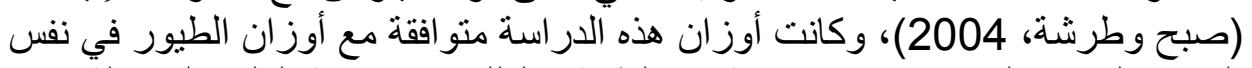

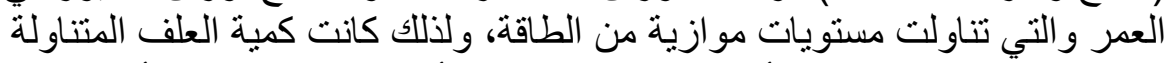

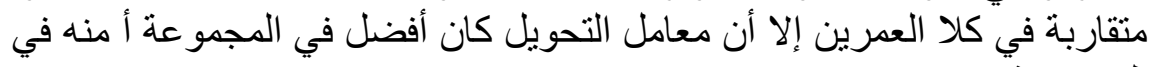

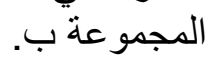

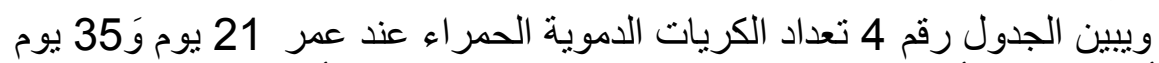

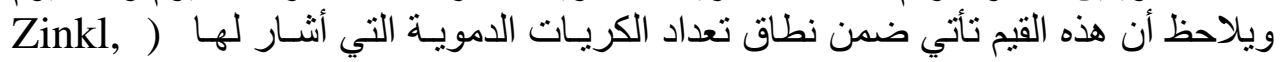


1986 ) و الذي يتر اوح بين 2.5 و 3.5 مليون/مل3، ولم بلم يلاحظ أب فروق معنوية بين

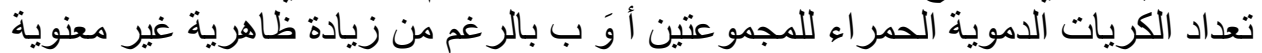

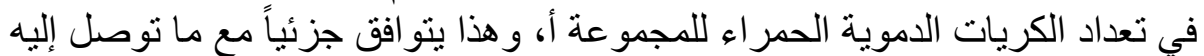
بينما أدت زيادة الطاقة إلى ارتفاع تعداد الكريات الحمر اء بشكل الئل

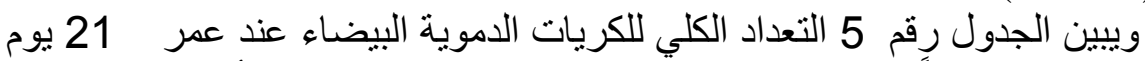
معنوي (P<0.05)

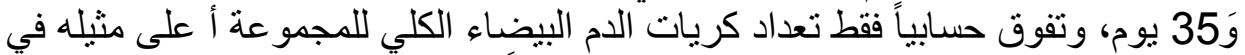

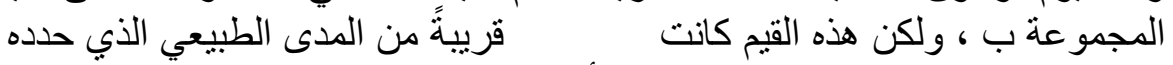

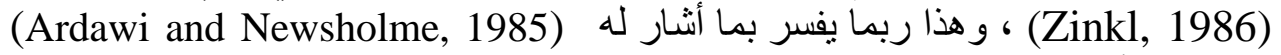
اللذين بينا أهمية الطاقة (كمصدر وقياء وقود) لتلبية عمليات الانقسام السريعة و الانتنشار بالنسبة

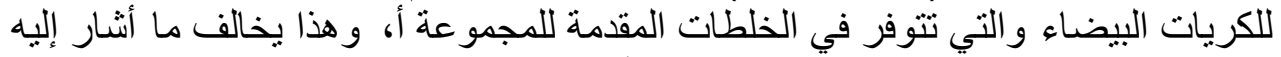
(Praharaj et al., 1999) مستوى الطاقة المستخدمة.

ويبين الجدول رقم 6 منوسط قيمة الكسر الحجمي للكريات ( PCV)

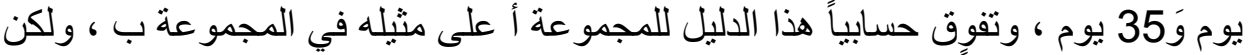

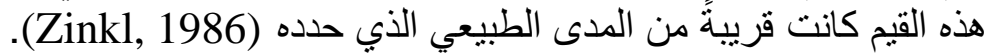

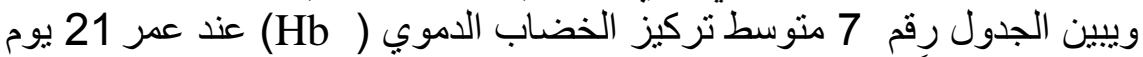

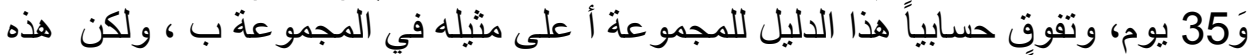
القيم كانت قريبةً من المدى الطبيعي الذي حدده (Zinkl, 1986).

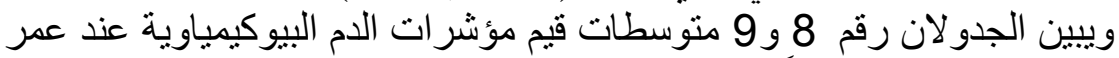

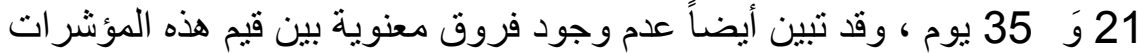

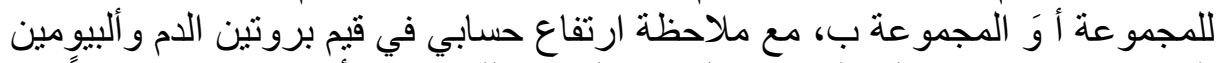

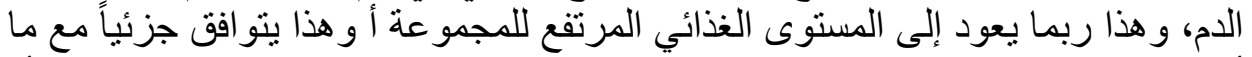

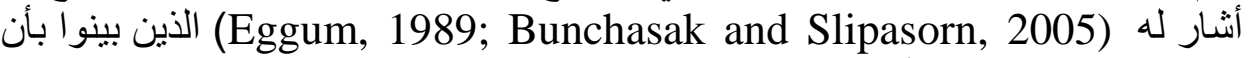

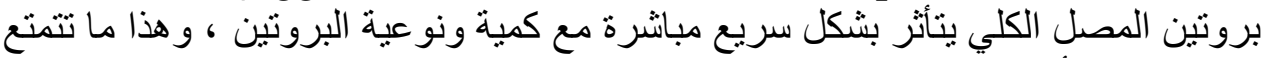

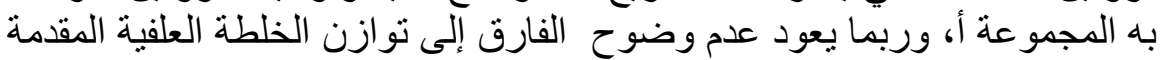

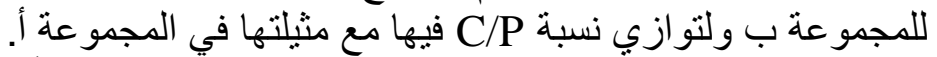

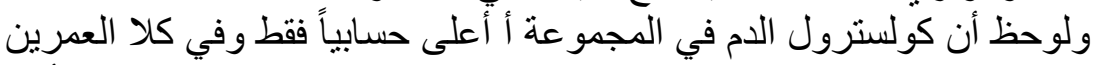

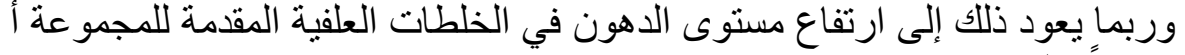

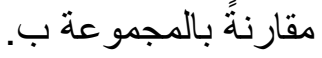

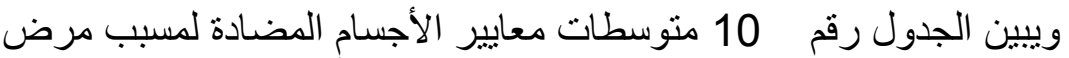

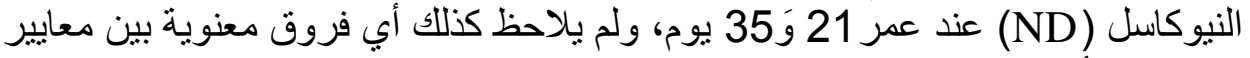

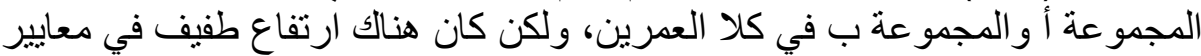

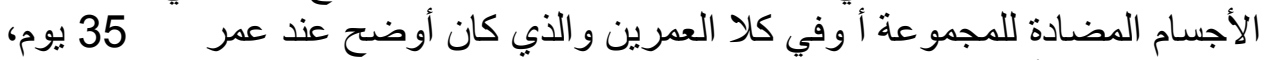

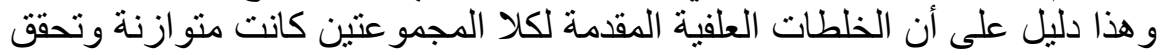

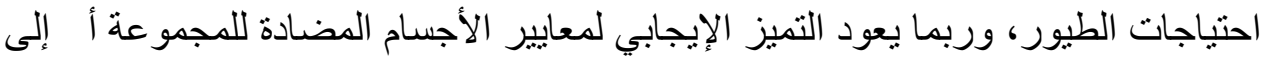

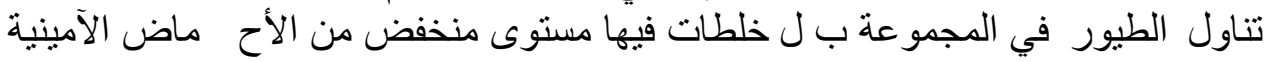




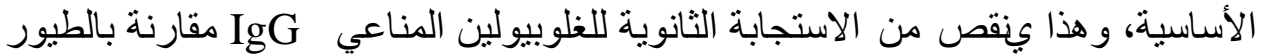

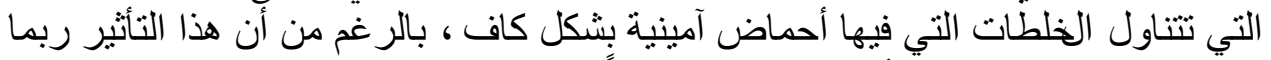

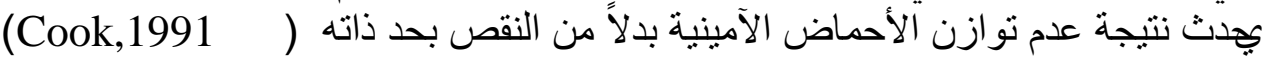

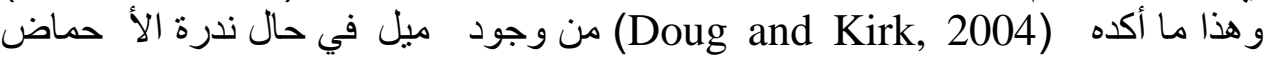
الآمينية الأساسية في الخلطة إلى إحداث نقص عام في الاستجابة الخلطية (الهمور الية) بينما يحدث تأثير أقل على المناعة الخلوية.

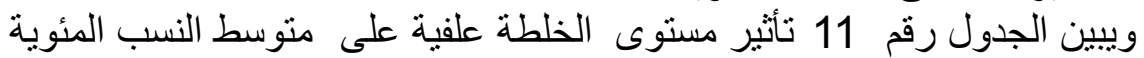

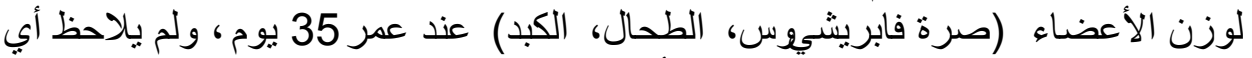

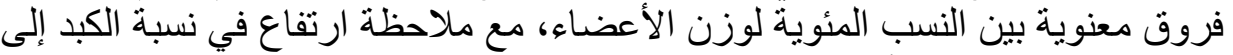

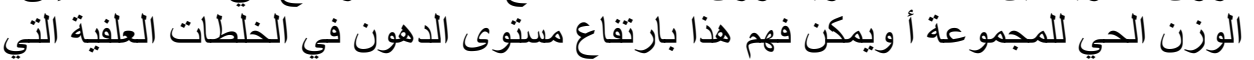

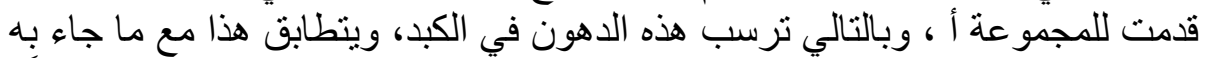

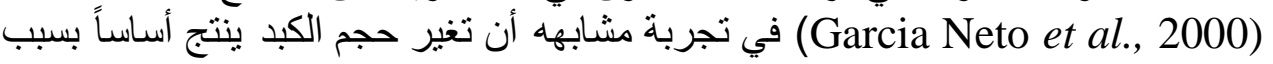
تغير مستوى الدهون في الكبد.

\section{استنتاجـات}

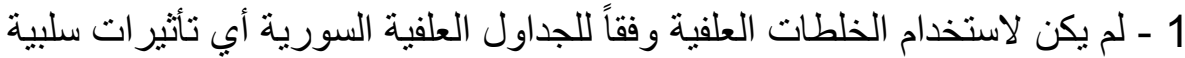

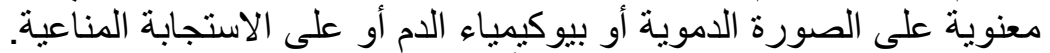

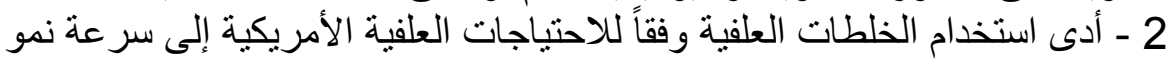
ومعامل تحويل أفضل من الخطات الخلطات العلفية السورية.

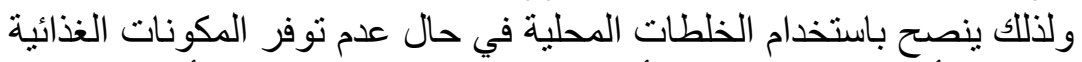

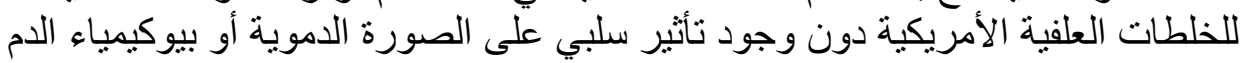
أو الاستجابة المناعية للطيور . للاعيك دون

\section{REFERENCES}

الجداول العلفية السورية (1987): القرار 45/ ت ، وزارة الزراعة والإصلاح الزراعي، دمثنق - سوريا.

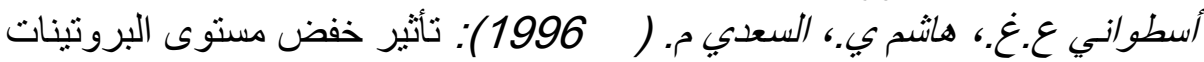

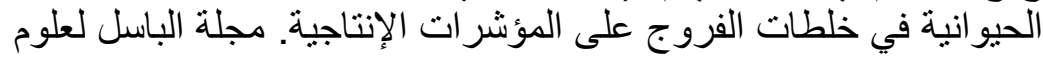

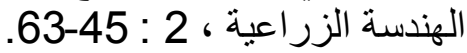

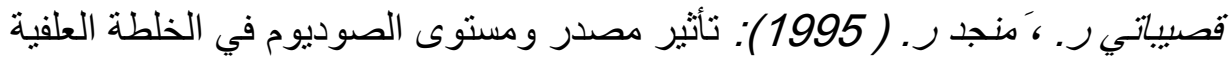

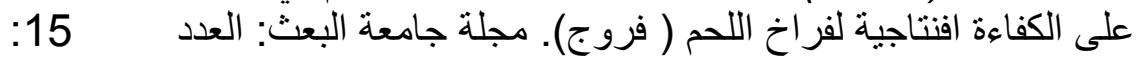
.11-101 صبح أ.م ، قصيياتي ر. كَ طرشة ح. (1998): استخدام البدائل العلفية المنتجة في سورية العزية في تغذية الفروج. مجلة البحوث الزر الزية اعية العربية، 2: 252-275. 


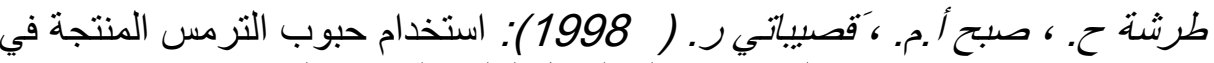

سورية في تغذية الفروج. مجلة الباسل لعلوم الهندسة الزر اعية، 6: 1988: 15-36.

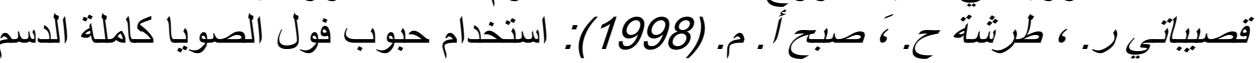

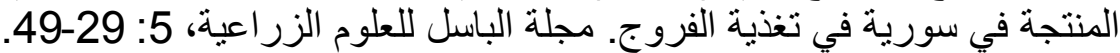

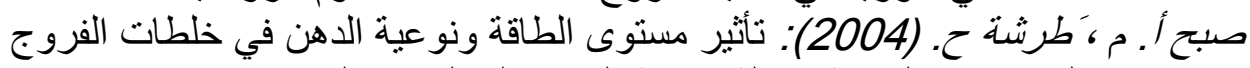

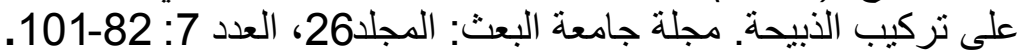

Al-Mayah, A.A. (2006): Immune Response of Broiler Chicks to DLMethionine Supplementation at Different Ages. Int. J. Poult. Sci., 5 (2): 169-172.

Ardawi, M.S. and Newsholme, E.A. (1985): Metabolism in lymphocytes and its importance in the immune response. Essays Biochem. 21: 1-44.

Bunchasak, C. and Silapasorn, T. (2005): Effects of adding methionine in low-protein diet on production performance reproductive organs and chemical liver composition of laying hens under tropical conditions. Int. J. Poult. Sci., 5: 301-308.

Butcher, G.D. and Miles, R.D. (2002): Interrelationship of Nutrition and Immunity .http:// www .edis.ifas.ufl.edu.

Campbell, TW.; Avian hematology and cytology. 2nd ed. Ames, IA: lowa State University press, (1995): 3-34. Lucas AM, Jamroz C. Atlas of avian hematology. Agricultural monograph 25.271. Washington, DC: United States Department of Agriculture, 1961.

Cook, M.E. (1991): Nutriton and the immune response of the domestic fowl. Crit-Rev. Poult. Biol., 3: 167-189.

Dein, FJ.; Hematology, In Harrison, GJ. and Harrison, LR. (eds) (1986): Clinical Avian Medicine and Surgery. Philadelphia, WB Saunders Co, pp 174-191.

Doug, K. and Kirk, K. (2004): Influence of nutrition on immune status of the bird. Proceedings of the 24th Technical Turkey conference. P43

Eggum, B.O. (1989): Biochemical and methodological principles. In: H.D. Bock, B. Eggum, A.G. Low, O. Simon and T. Zebrowska (eds), Protein metabolism in farm animals. Evaluation, Digestion, Absorption and Metabolism, (Oxford 
Science Publication, Deutscher Handwirtschafts Verlag, Berlin), 1-52.

Garcia Neto, M.; Pesti, G.M. and Bakalli, R.I. (2000): Influence of Dietary Protein Level on the Broiler Chicken's Response to Methionine and Betaine Supplements. Poultry Science 79: 1478-1484.

Glick, B.; Day, E.J. and Thompson, D. (1981): Calorie-protein deficiencies and the immune response of the chicken. I. Humoral immunity. Poult. Sci. 60: 2494-2500.

Hawkey, CM. and Dennett, TB. (1989): Color Atlas of Comparative Veterinary Hematology. London, Wolfe Medical Publications, Ltd, 1989.

Kidd, M.T.; Peebles, E.D.; Whitmarsh, S.K.; Yeatman, J.B. and R.F. Wideman, Jr. (2004): Growth and immunity of broiler chicks as affected by dietary arginine. Poultry Sic. 80: 1535-1542.

Lu, H. (2007): Avian Virology Diagnostic Protocols and procedure. (Standard operation procedure-SOPs). Preparation For Avian Influenza Laboratory Consultancy.Under Fao And Usaid.

National Research Council, (1994): Nutrient requirements of Poultry. $9^{\text {th }}$ edition (Revised). National Academy press Washington, DC.

Praharaj, N.K.; Reddy, M.R.; Rama Rao, S.V.; Shyamsunder, G. and Reddy, B.L.N. (1999): Energy by sire family interactions for growth, feed efficiency, immune competence in commercial broilers. Arch. Geflu“" gelkd. 63: 82-86.

SPSS Statistical 17.0 (2008): Statistical Package for Social SciencesVersion 17.0. Computer software 17.0, SPSS Inc., Headquarters. Wacker Drive, Chicago, lllinois 60606, USA.

Zinkl, JG. (1986): Avian hematology .Jain NC,ed. Schalm's veterinary hematology.4th ed .Philadelphia, 256-273. 
جدول رقم (1 )

تركيب الغلطات العافية المستفدمة في هرملتي الرعاية.

\begin{tabular}{|c|c|c|c|c|}
\hline \multicolumn{2}{|c|}{ المجموعة ب } & \multicolumn{2}{|c|}{ المجموعة أ } & \multirow{2}{*}{ المواد العلقية \% } \\
\hline 35-22 يوم & 21-1 يوم & 35-22 يوم & 1-1-1 يوم & \\
\hline 63.62 & 58.8 & 55.95 & 49.93 & ذرة صفراء \\
\hline 31.9 & 37 & 36 & 42 & كسبة فول الصويا \\
\hline 0.4 & 0.2 & 4 & 4 & زيت صويا \\
\hline 2.1 & 2.05 & 2.05 & 2.05 & فوسفات ثنائية الكالسيوم \\
\hline 0.74 & 0.74 & 0.74 & 0.74 & كريونات الكالسيوم \\
\hline
\end{tabular}




\begin{tabular}{|c|c|c|c|c|}
\hline 0.16 & 0.18 & 0.18 & 0.2 & ميثيونين حر \\
\hline 0.1 & 0.05 & 0.1 & 0.1 & لايسين حر \\
\hline 0.3 & 0.3 & 0.3 & 0.3 & ملح طعام ميود \\
\hline 0.1 & 0.1 & 0.1 & 0.1 & كلوريد الكولين \\
\hline$* * 0.1$ & $* * 0.1$ & $* 0.1$ & $* 0.1$ & خلطة الفيتامينات \\
\hline$* * 0.1$ & $* * 0.1$ & $* 0.1$ & $* 0.1$ & خلطة المعادن \\
\hline 0.23 & 0.23 & 0.23 & 0.23 & بيكربونات الصوديوم \\
\hline 0.05 & 0.05 & 0.05 & 0.05 & مضاد الكوكسيديا \\
\hline 0.1 & 0.1 & 0.1 & 0.1 & مضاد سموم فطرية \\
\hline 100 & 100 & 100 & 100 & المجموع \\
\hline
\end{tabular}

* كل 1كغ من العلف الجاهز يحتوي على الفيتامينات والمعادن النادرة اللازمة وفقاً

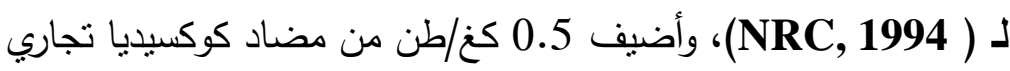
* * كل 1كغ من العلف الجاهز يحتوي على الفيتامينات والمعادن النادرة اللازمة

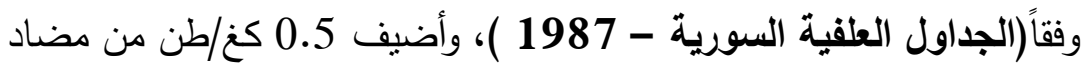
كوكسيديا تجاري.

جدول رقم (2 ) تهليل الغلطات العلفية وقيمها الغذانية مسابيك.

\begin{tabular}{|c|c|c|c|c|}
\hline \multicolumn{2}{|c|}{ المجموعة ب } & \multicolumn{2}{|c|}{ المجموعة أ } & \multirow{2}{*}{ المكونات الغذائية } \\
\hline 35-22 يوم & 1-1-1 يوم & 35-22 يوم & 21-1 يوم & \\
\hline 2901 & 2832 & 3069 & 3006 & الطاقة القابلة للتمثيل كيلو كالوري/كغ \\
\hline 19.39 & 21.12 & 20.51 & 22.43 & البروتين الخام \% \\
\hline 149.61 & 134.01 & 149.58 & 134.02 & الطاقة/البروتين \\
\hline 1.1 & 1.19 & 1.19 & 1.3 & اللايسين \% \\
\hline 0.46 & 0.5 & 0.49 & 0.53 & الميثيونين \% \\
\hline 0.78 & 0.85 & 0.83 & 0.9 & المثيونين + السيستين \% \\
\hline 0.22 & 0.25 & 0.24 & 0.27 & التربتوفان \% \\
\hline 0.9 & 0.95 & 0.91 & 0.96 & الكالسيوم \% \\
\hline
\end{tabular}


Assiut Vet. Med. J. Vol. 57 No. 129 April 2011

\begin{tabular}{|c|c|c|c|c|}
\hline 0.64 & 0.63 & 0.63 & 0.63 & الفوسفور الكلي \% \\
\hline 0.41 & 0.42 & 0.42 & 0.42 & الفوسفور المتاح \% \\
\hline 0.17 & 0.17 & 0.17 & 0.17 & الصوديوم \% \\
\hline 0.22 & 0.21 & 0.21 & 0.21 & الكلور \% \\
\hline 1.74 & 1.37 & 3.55 & 3.24 & حمض اللينوليك \% \\
\hline 3.96 & 4.26 & 4.11 & 4.46 & الألياف \% \\
\hline
\end{tabular}

* - - الطاقة/البروتين :هي نسبة تعد مؤشرًا لرفع المكونات الغذائية عند زيادة تركيز

الطاقة والعكس صحيح عند انخفاضها.

\begin{tabular}{|c|c|c|c|c|}
\hline \multicolumn{2}{|c|}{ المجموعة ب ب } & \multicolumn{2}{|c|}{ المجموعة أ } & \multirow{2}{*}{ المكون الغذائي } \\
\hline 35-22 يوم & 21-1 يوم & 35-22 يوم & 21-1 يوم & \\
\hline 19.08 & 20.94 & 20.26 & 22.15 & البروتين الخام \% \\
\hline 5.9 & 6.19 & 8.3 & 7.73 & نسبة الدهن الخام \% \\
\hline 3.9 & 4.02 & 5.34 & 6.32 & نسبة الرماد \% \\
\hline 89.15 & 90.75 & 88.67 & 88.21 & نسبة المادة الجافة \% \\
\hline
\end{tabular}

\section{جدول رقم ( 3 ) ) \\ متوسط الأوزان والعثف المستمشك وممعامل التمويل \\ عند عمر 21 و 35 يون.}

\begin{tabular}{|c|c|c|}
\hline خلمتوى الغذائي ( ب منضة ) & المستوى الغذائي ( أ ) & المجموعة \\
\hline 533.55 & 564.32 & متوسط الوزن غ \\
\hline 832 & 853.6 & كمية العلف المستهلك غ \\
\hline 1.56 & 1.51 & معامل التحويل \\
\hline
\end{tabular}


Assiut Vet. Med. J. Vol. 57 No. 129 April 2011

\begin{tabular}{|c|c|c|c|}
\hline 1169.85 & 1281.5 & متوسط الوزن غ & م \\
\hline 2300.1 & 2244.1 & كمية العلف المستهلك غ غ & \\
\hline 1.95 & 1.75 & معامل التحويل & \\
\hline
\end{tabular}

الجدول رقمر 4 ):

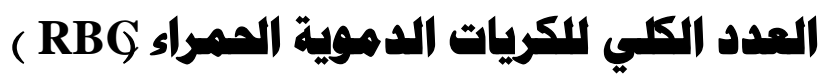

مع الفطأ المعياري عند دجاج اللمم (روص308 ) عند عمر 21 و 35

يومها.

\begin{tabular}{|c|c|c|c|c|}
\hline \multicolumn{2}{|c|}{ المستوى الغذائي ( ب منظة ) } & \multicolumn{2}{|c|}{ 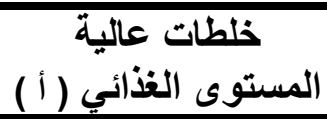 } & المجموعة \\
\hline المعياري & المتوسط & المعياري & المتوسط & موعد السحب \\
\hline 0,13 & 2,53 & 0,17 & 2,55 & 21 يوم \\
\hline
\end{tabular}


Assiut Vet. Med. J. Vol. 57 No. 129 April 2011

\begin{tabular}{|c|c|c|c|c|}
\hline 0,17 & 2,61 & 0,12 & 2,63 & 35يوم \\
\hline \multicolumn{4}{|c|}{$3,5-2,5$} & مجالات القيم المرجعية \\
\hline \multicolumn{4}{|c|}{ مليون كرية في الملم مكعب من الدم } & وحدة القياس \\
\hline
\end{tabular}

\section{البدول رقم) 5 (1) ):}

متهوسط العدد الكي للكريات الدموية البيضاء WBC )

مع الغطأ المعياري عند دجاه اللمم (روصن308 ) عند عمر 21 و 35

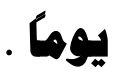

\begin{tabular}{|c|c|c|c|c|}
\hline \multicolumn{2}{|c|}{ خلمتات منظفى الغذائي (ب ) } & \multicolumn{2}{|c|}{ خلطات عالية المستوى الغذائي ( أ) } & المجموعة \\
\hline الالانحراف & المتوسط & المعياري & المتوسط & موعد السحب \\
\hline 3.8 & 12,833 & 3 & 13,889 & 21 يوم \\
\hline
\end{tabular}


Assiut Vet. Med. J. Vol. 57 No. 129 April 2011

\begin{tabular}{|c|c|c|c|c|}
\hline 5,8 & 17,429 & 5,3 & 18,8 & 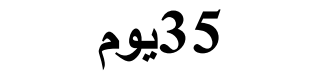 \\
\hline \multicolumn{4}{|c|}{$30-12$} & مجالات القيم المرجعية \\
\hline \multicolumn{4}{|c|}{ ألف كرية في الملم مكعب من الدم } & وحدة القياس \\
\hline
\end{tabular}

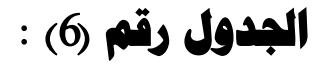 \\ متوسط قيمة الكسر المبمي للكريات PCV) \\ مع النمأ المعياري عند الفروه (روص308 ) عند عمر21 و 35 يومكا .}

\begin{tabular}{|c|c|c|c|c|}
\hline \multicolumn{2}{|c|}{ المستوى الغذائي (بخفة ) } & \multicolumn{2}{|c|}{ خلطات عالية المستوى ألغائي ( ) } & \multirow{2}{*}{ موعد السحب } \\
\hline الالاعحراف & المتوسط & الالأحمرافي & المتوسط & \\
\hline 1,42 & 29,55 & 1.71 & 30,61 & 21 يوم \\
\hline 2,25 & 29,8 & 2,95 & 31,2 & 35يوم \\
\hline \multicolumn{4}{|c|}{$35-22$} & مجالات القيم المرجعية \\
\hline \multicolumn{4}{|c|}{$\%$} & وحدة القياس \\
\hline
\end{tabular}




\section{البدول رقم (7) :}

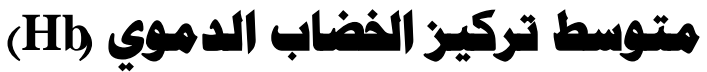

\section{مع الفطأ المعياري عند الفروج(روص308 ) عند عمر 21 و 35 يوهك.}

\begin{tabular}{|c|c|c|c|c|}
\hline \multicolumn{2}{|c|}{ 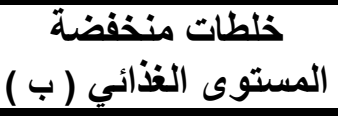 } & \multicolumn{2}{|c|}{ خلطات عالية المستوى الغذي ( ) } & المجموعة \\
\hline الالعياري & المتوسط & الالأحمرافي & المتوسط & موعد السحب \\
\hline 1,6 & 9,97 & 1,4 & 10,33 & 21 يوم \\
\hline 0,98 & 10,63 & 1,17 & 11,04 & 35يوم \\
\hline \multicolumn{4}{|c|}{$13-7$} & مجالات القيم المرجعية \\
\hline \multicolumn{4}{|c|}{ غ غلدل } & وحدة القياس \\
\hline
\end{tabular}




\section{الجدول رقم ( 8 )}

متوسطات قيم موثشرات الدم البيوكيمياوية عند عمر2 يوم.

\begin{tabular}{|c|c|c|c|c|c|}
\hline \multicolumn{2}{|c|}{ المستوى الغذائي ( ب ) } & \multicolumn{2}{|c|}{ خلطات عالية المستوى } & \multicolumn{2}{|r|}{ المجموعة } \\
\hline الالأحرافي & المتوسط & اللعياري & المتوسط & اللواحدة & الدم البيوكيمياوية \\
\hline $5.06 \pm$ & 21.57 & $5.82+$ & 25.63 & غال & بروتين الام \\
\hline $2.78+$ & 11.89 & $4.52+$ & 14.56 & غال & الألبيومين \\
\hline $34.25+$ & 241.42 & $41.36+$ & 248.1 & ملغ/دل & سكر الام \\
\hline $24.31 \pm$ & 77.81 & $22.05+$ & 77.21 & ملغ/دل & الثحوم الثلاثية \\
\hline $19.68+$ & 116.53 & $10.6+$ & 122.85 & ملغ/دل & الكولسترول \\
\hline $10.81 \pm$ & 50.11 & $6.66 \pm$ & 50.20 & ملغ/دل & 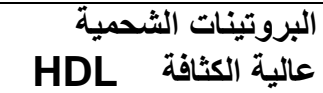 \\
\hline $13.75+$ & 66.77 & $7.22 \pm$ & 69.71 & ملغادل & LDL البروتينات الثخمية \\
\hline
\end{tabular}




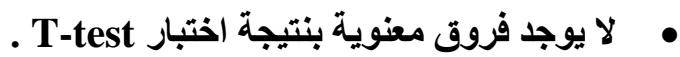

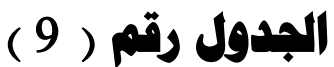

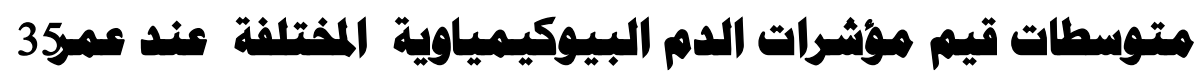

pes

\begin{tabular}{|c|c|c|c|c|c|}
\hline \multicolumn{2}{|c|}{ خلطتوى الغذائي ( ب ) } & \multicolumn{2}{|c|}{ المستوى الغذائي ( ألية ) } & \multicolumn{2}{|r|}{ المجموعة } \\
\hline الالمعياري & القيمة & الالمعرافي & القيمة & الواحدة & الام البيوكيمياوية \\
\hline 5.99+ & 24.35 & $6.22 \pm$ & 27.34 & غال & بروتين الدم \\
\hline $2.48 \pm$ & 14.48 & $5.02 \pm$ & 15.84 & غار & الألبيومين \\
\hline $16.55 \pm$ & 226.99 & $28.12+$ & 239.22 & ملغ/دل & سكر الدم \\
\hline $10.14+$ & 68.94 & $8.85 \pm$ & 70.03 & ملغ/دل & الثحوم الثلاثية \\
\hline 10.99+ & 123.91 & $11.4 \pm$ & 131.61 & ملغ/دل & الكولسترول \\
\hline $10.12 \pm$ & 59.1 & $7.65 \pm$ & 58.42 & ملغ/دل & 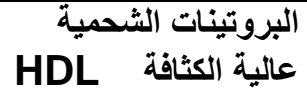 \\
\hline
\end{tabular}


Assiut Vet. Med. J. Vol. 57 No. 129 April 2011

\begin{tabular}{|c|c|c|c|c|c|}
\hline $8.99+$ & 61.3 & 9.53+ & 62.98 & ملغ/دل & البروتينات الثخافة الكمية \\
\hline
\end{tabular}

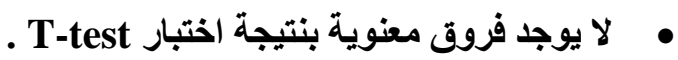

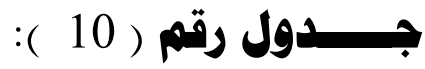

متوسطات معايير الأجسام المادة لمببب مرض النيوكاسل (ND)

\begin{tabular}{|c|c|c|c|c|}
\hline \multicolumn{2}{|c|}{35 يوم } & \multicolumn{2}{|c|}{21 يوم } & \multirow[b]{2}{*}{ المجموعات التجريبية } \\
\hline المعياري & الأجسام المضادة معيارة & المعياري & $\begin{array}{c}\text { الأجسام المضطادة معيارة } \\
\text { (Log2) }\end{array}$ & \\
\hline $12.36 \pm$ & 21 & $7.83 \pm$ & 12.25 & خلطات عالية ألمستوى الغذائي \\
\hline $11.15 \pm$ & 16.35 & $5.38 \pm$ & 11.5 & خلطات منذفضة المستوى \\
\hline
\end{tabular}

• كل قيمة في هذا الجدول هي متوسط لـ 20 عينة مكرر.

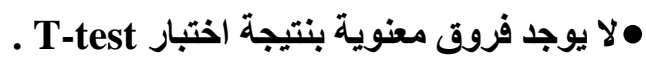

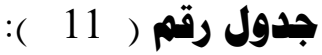

تأثير هستوى الخلطة علفية على هتوسط النسب المئوية لوزن الأعضاء (صرة فابريشيوس، الطحال،الكبد) \pm الانخراف المعياري عند عمر 35 يوم 
Assiut Vet. Med. J. Vol. 57 No. 129 April 2011

\begin{tabular}{|c|c|c|c|c|}
\hline \multicolumn{2}{|c|}{ المجموعة ب } & \multicolumn{2}{|c|}{ المجموعة أ } & \multirow{2}{*}{ الأعـضـاء } \\
\hline الانحرياف & 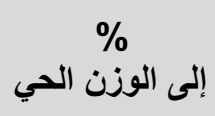 & الانحراف & إلى الوزن الحي & \\
\hline $0.0026 \pm$ & 0.169 & $0.0015 \pm$ & 0.17 & صرة فابريشيهس\% \\
\hline $0.098 \pm$ & 0.126 & $0.021 \pm$ & 0.122 & الطـــال\%\% \\
\hline $0.287 \pm$ & 2.66 & $0.269 \pm$ & 2.9 & الكــــب \% \\
\hline
\end{tabular}

• الا يوجد فروق معنوية بنتيجة اختبار T-test 